\title{
Halbwachs no Collège de France ${ }^{1}$
}

\author{
Laurent Mucchielli \\ Centre Nationale de La Recherche Scientifique (CNRS) e Centre de \\ Recherches Sociologiques sur le Droit et les Institutions Pénales (CESDIP) \\ Jacqueline Pluet-Despatin \\ Maison des Sciences de l'Homme (MSH) e Institut \\ Mémoires de l'Édition Contemporaine (IMEC)
}

\section{RESUMO}

Este artigo apresenta documento escrito por Maurice Halbwachs, em seus cadernos de memória. Seu principal tema é a eleição de Halbwachs para o Collège de France. Palavras Chave: memória; história das ciências; durkheimismo.

\section{ABSTRACT}

This article presents the document writen by Maurice Halbwachs, in his memorybooks. Its main subject is the Halbwachs election for the Collège de France.

Keywords: memory; science history; durkheimism. 


\section{UMA LONGA ESPERA}

Quando Halbwachs se decide a colocar sua candidatura à sucessão de Mauss, não é a primeira vez que ele se apresenta a uma eleição para o Collège de France.

No início de 1929 falece Jean Izoulet, titular da cátedra de Filosofia Social desde 1897. Na época, ele havia sido preferido a Durkheim, e isto havia ficado em todas as memórias. O jogo é portanto ao mesmo tempo pessoal e coletivamente simbólico para os durkheimianos. Entre eles, Mauss é naturalmente o candidato mais legítimo para esta eleição. Sobrinho e principal colaborador de Durkheim, diretor da segunda série de Année sociologique, co-fundador do Institut d'ethonologie de Paris, personalidade científica de reputação internacional, ele é a figura emblemática da sociologia francesa naquele momento. E de fato, é ele quem a levará ao final de uma áspera batalha ${ }^{2}$. Todavia, sem pretender rivalizar com Mauss e evitando fazer qualquer coisa que pudesse embaraçá-lo, Halbwachs se inscreve desde então na corrida por uma eleição futura. Em 11 de junho, escreve a Mauss para preveni-lo de que vai se apresentar como candidato num primeiro momento, para marcar presença, e em seguida apagar-se diante dele: "É muito provável que eu não vá até o fim e que não envie a carta oficial (...). Como haverá proximamente um certo número de vagas novas no Collège, quero ter lugar reservado. Não sei o que vai acontecer quando Loisy se for, e se, estando no Collège, o senhor não pedirá a transformação de sua cadeira, o que liberaria a Sociologia. Não sei tampouco se será possível criar uma cadeira de Estatística Moral. ${ }^{\text {’3 }}$ De fato, Halbwachs não se apresenta senão em segunda linha, o que não deixa de constituir um jogo pois que tem contra si os dois outros candidatos: o médico-antropólogo Georges Papillault e o filósofo André Joussain. Papillault, membro do grupo dos raciólogos herdeiros de Broca, ensina Sociologia na École d'Anthropologie de Paris e Antropologia na École Pratique des Hautes Études. A "bio-sociologia" que ele defende contra o que chama a "filosofia" dos durkheimianos prolonga um combate importante travado por esses últimos, antes da guerra ${ }^{4}$. É um pretendente sério e Halbwachs não o ultrapassará senão em segundo turno, por esse voto em segunda linha ${ }^{5}$.

Além de preparar seu futuro, Halbwachs está certamente motivado também pela competição, senão pela rivalidade que existe no seio do grupo dos strasbourguenses, pois que Lucien Febvre, Marc Bloch, Albert Grenier, Charles Blondel e até Edmond Vermeil se posicionarão oficial ou oficiosamente ${ }^{6}$. Este olhar invejoso voltado com insistência para Paris, dos professores nomeados à nova universidade de Strasbourg em 1919, logo após a vitória, não se explica somente pela evolução lógica da carreira dos mais renomados entre eles. Corresponde também ao momento do declínio dessa universidade que havia no entanto simbolizado uma renovação e insuflado um dinamismo real no conjunto do meio universitá- 
rio francês. Desde o final de 1925, seu decano Christian Pfister o constata amargamente: "Esta faculdade que havia sido criada tão sólida vai se deslocar, os melhores elementos nos escapam. É preciso se resignar com isso: nós teremos a glória de ser a antecâmara da Sorbonne." ${ }^{" 7}$ De fato, Halbwachs sonha com isso desde o final dos anos 20 e em seguida o manifesta cada vez mais. Com efeito, ele vai logo tentar aproveitar todas as oportunidades que se apresentarem e paralelamente desfraldar uma atividade institucional parisiense muito importante ${ }^{8}$.

Ao final de 1930, Halbwachs espera que a Sorbonne crie uma cátedra de "Sociologia Estatística" que acaba não se concretizando". No final do ano seguinte, é Simiand quem se prepara para entrar no Collège de France (na cátedra de História do Trabalho deixada vaga pela morte de Georges Renard), o que não pode senão ampliar em Halbwachs o sentimento de que, afinal de contas, agora era sua vez. Em 1932, como previsto, Loisy se aposenta. Apoiado por Mauss, Halbwachs anuncia rapidamente suas intenções a seus amigos, mas encontra-se então em concorrência com Febvre e, diante das melhores chances deste, renuncia a apresentar oficialmente sua candidatura para não comprometer o êxito de seu colega historiador ${ }^{10}$. Ao mesmo tempo, Fauconnet se torna titular de uma cátedra da Sorbonne que, pela primeira vez, é chamada simplesmente "Sociologia". Halbwachs agita-se. Em 6 de maio de 1934, escreve em seu diário: "Passei em Paris os três últimos meses deste ano no qual substitui Simiand no Conservatoire des Arts et Métiers (...) é possível que Piganiol retorne a Strasbourg. Quanto a mim, não conto senão com o Conservatoire. Mas pode ser que Vessiot se aposente, e que Bouglé se torne diretor da École [Normale Supérieure]. Isso deixa uma perspectiva." ${ }^{11}$ De fato, é por Bouglé que uma primeira oportunidade se concretiza.

Em 1935, Bouglé é nomeado diretor da École Normale Supérieure e propõe a Halbwachs que o substitua na cátedra de História da Economia Social da Sorbonne (e se torne paralelamente sub-diretor do Centre de Documentation Sociale que Bouglé dirige na $\mathrm{ENS}^{12}$ ). Essa posição é frágil e, no mesmo ano, Halbwachs apresenta novamente sem sucesso sua candidatura ao Collège de France, para a sucessão de Édouard Fuster ${ }^{13}$. Depois, em 1937, em seguida a uma operação administrativa complicada, a cátedra de Bouglé é de alguma forma trocada por uma de Pedagogia, imediatamente transformada em cátedra de Metodologia e Lógica das Ciências, confiada a Halbwachs como titular ${ }^{14}$. Ele conseguiu então retornar a Paris. No entanto, sua carreira vai ter ainda muitas peripécias.

Em 1939, com a morte de Fauconnet, Halbwachs pede e obtém imediatamente sua transferência para a cátedra de Sociologia. Mas ele a ocupa por um ano apenas. Em janeiro de 1940, Bouglé morre e Halbwachs o sucede na direção do Centre de Documentation Sociale. Paralelamente (mas exatamente, por quais 
razões administrativas?), a assembléia dos professores "propõe uma troca e pede que Halbwachs seja nomeado titular da antiga cátedra de Bouglé."15 Halbwachs se torna, portanto, professor de História da Economia Social na Sorbonne. Estamos em 1941. Após a derrota, instalou-se o governo de Vichy que, pelas leis de julho e outubro de 1940, procede a uma depuração anti-semita da função pública. Mauss é obrigado a se demitir de seu posto de presidente da Vème section da École Pratique des Hautes Études e de sua cátedra no Collège de France ${ }^{16}$. O caminho do Collège de France se abre então novamente diante de Halbwachs. Quaisquer que sejam suas ambições pessoais ${ }^{17}$, trata-se de defender a única cátedra de Sociologia do Collège e de prolongar o mais possível toda uma história, a do durkheimismo. Quando Mauss é oficialmente aposentado (em junho de 1941), Halbwachs começa a preparar sua campanha.

\section{ELEMENTOS PARA A HISTÓRIA E A SOCIOLOGIA DAS CIÊNCIAS}

O relato por Halbwachs de sua campanha para o Collège de France constitui um documento excepcional do ponto de vista da História e da Sociologia das Ciências. Ele permite, de fato, observações empíricas originais em diversos planos.

O relato nos mostra de início o percurso intelectual e acadêmico do autor. Beneficiário de uma posição sólida no campo universitário, Halbwachs, tido como "reservado, quase tímido" 18 , afirma suas ambições e sabe colocá-las em ação por meio de uma rede de relações e de amigos que cultiva de longa data. Desse modo, aplica sua estratégia com um método e uma precisão bem científicos. Nada lhe escapa da carreira de seus colegas e concorrentes. Com isso, manifesta gosto pela justa e se diverte com ela, como o demonstra a galeria de retratos que desenha, muitas vezes com júbilo e sempre sem indulgência exagerada (indo mesmo, por vezes, a julgamentos que sabe serem injustos). Sem dúvida, é a lei do gênero e um traço do meio acadêmico - constatado, por exemplo, com as correspondências de Lucien Febvre e Marc Bloch - essa causticidade ritual em relação aos "caros colegas", a qual assinala de alguma forma o pertencimento à comunidade.

Em seguida, durante as visitas que ele efetua junto aos eleitores influentes do Collège de France que visita, Halbwachs tece uma espécie de prosopografia que sublinha a importância dos laços geracionais que unem os universitários entre si nessa época (na qual eles eram, é verdade, muito menos numerosos que hoje e essencialmente concentrados em Paris, onde também moravam). Esses laços vão do simples conhecimento recíproco que provoca um rápido enternecimento e a evocação de algumas lembranças comuns da École Normale Supérieure, até a união das famílias pelo casamento, implicando uma forte solidariedade e rela- 
ções de dom/contra-dom. Entre eles, esses normalistas agrégés de letras se conhecem, em geral, muito bem, tratam-se intimamente por vezes, nutrem em geral simpatias ou antipatias desde a idade de vinte anos. E essas amizades podem trazer uma outra consideração. Halbwachs experimentou isso com Febvre.

Terceiro ponto: a campanha de Halbwachs se desenrola em 1942 e 1943, em plena Ocupação, a qual pesa muito sobre a vida acadêmica. Além disso, foi um evento político que desencadeou a iniciativa de Halbwachs: a aposentadoria forçada de Mauss pela aplicação das leis anti-semitas. Porém há mais. Além das questões científicas, que são o motivo anunciado das visitas de candidatura, Halbwachs indica em muitas passagens que, nas conversações, importam muito a guerra e a Ocupação. Trata-se claramente do primeiro assunto abordado nos encontros, ou o último antes da separação. E a troca que acontece nessa ocasião corre o risco de ter um papel não negligenciável sobre o futuro desta candidatura, se bem que Halbwachs seja, naturalmente, muito prudente. Prudência relativa, no entanto, pois ele registra em seu caderno, em 1944, as simpatias pela resistência ou, ao contrário, pelo regime em vigor, e até mesmo os que aderem ao anti-semitismo.

Enfim, este documento esclarece de modo surpreendente certos jogos interiores no campo intelectual e no campo acadêmico. Com efeito, o relato de Halbwachs confirma que as solidariedades normalistas, por antigas que sejam, e o contexto político, embora onipresente, estão longe de explicar satisfatoriamente as clivagens e as alianças que se amarram em torno dessa eleição. Para empregar as palavras de Pierre Bourdieu, diríamos que o campo científico conserva claramente uma forte autonomia relativa. Também, enquanto o texto expõe sobretudo as solidariedades ligadas à "camaradagem”, a eleição final parece depender do campo específico no qual ela se realiza. Assim, Halbwachs escreve que:

Em suma, tive contra mim os filósofos católicos, a Academia francesa, os clericais, o único representante (grande burguês) da Académie des sciences morales et politiques, os científicos reacionários. Tive a meu favor quase todos os lingüistas, os eruditos especialistas das diversas civilizações (...), os historiadores, os científicos avançados, sobretudo quatro biologistas (ou médicos). (...) Em suma, filosofia metafísica e religiosa, literatura pura, ciência dos estúpidos, contra a história sociológica, psicologia científica, lingüistica e biologia. Tudo isso era natural.

Halbwachs raciocina aqui em termos de famílias de pensamento, de concepções filosóficas da verdade. Opõe, no fundo, a família racionalista das "ciências positivas”, a tradição de Descartes, Bacon, Auguste Comte, etc., a um agrupamento irracionalista composto de espiritualistas, literatos e pobres engenheiros 
(claramente é assim que ele vê os físicos). Impossível dizer se esse ponto de vista reflete fielmente a realidade das motivações de uns e de outros ${ }^{19}$, mas a concepção que Halbwachs tem dessa clivagem no seio da instituição não deixa dúvida, o que é em si um elemento muito interessante. De fato, como assinalam - cada uma à sua maneira - todas as contribuições reunidas neste dossiê, o conjunto da Sociologia de Halbwachs testemunha a persistência de uma postura filosófica racionalista determinante de uma série de posturas teóricas e metodológicas. Em 1943, esta postura já parecia sem dúvida obsoleta aos olhos de uma parte dos jovens sociólogos e ela nos surpreende ainda mais nos dias atuais. No entanto, o sociólogo deve evitar considerá-la como um simples arcaísmo intelectual. Mais refinadamente, pode observar que a maneira pela qual Halbwachs analisa o resultado de sua eleição indica que essas questões de filosofia geral recortavam as práticas profissionais e as posições políticas, remetendo também, em parte, a posições sociais diferentes.

\section{A ELEIÇÃO}

A consulta aos arquivos do Collège de France permite precisar as etapas administrativas da eleição de Halbwachs e traz elementos acerca do conteúdo das relações anunciadas à assembléia de professores pela apresentação dos candidatos.

A eleição se faz ,segundo a regra, em duas etapas.

Primeiro, os professores devem se pronunciar sobre a manutenção ou não da cátedra que Mauss ocupava. Após haver recebido garantias financeiras do ministério, a assembléia se reúne para examinar os programas de ensino apresentados. Estamos em 14 de março de 1943. Nessa data, Halbwachs sabe que sua proposição (Psicologia Coletiva), defendida por Henri Piéron, deve bater a de Henri Gouhier (História das Ciências Morais na Idade Moderna), defendida por Étienne Gilson, e a de Auguste Renaudet (História do Humanismo Moderno), defendida por Lucien Febvre. No seu discurso (em parte inspirado por um texto ad hoc redigido por Halbwachs), Piéron faz valer a manutenção de uma "tradição francesa" de psicologia coletiva (ou sociologia psicológica, como se dizia na época). Ele evoca a memória de Tarde, antigo professor do Collège de France, "que soube criticar o antipsicologismo" de Durkheim, depois reconhece a este último o grande mérito de ter criado "todo um movimento de pensamento" e de haver mostrado que "a influência formadora do meio social é de uma importância capital para a compreensão da psicologia humana". Ele prepara assim habilmente sua apresentação de Halbwachs como o homem que "realiza uma verdadeira síntese dos pontos de vista opostos de Tarde e de Durkheim, nos quais se exasperava o antagonismo das teses filosóficas do individualismo e do sociologismo". 
Halbwachs "integra o social na psicologia individual" e, ao mesmo tempo, "mostra que os fatos sociais não podem ser compreendidos sem apelo às reações que as representações coletivas suscitam no pensamento dos indivíduos; em suma, ele é o homem sábio, o aglutinador, teve a largueza de visão própria de um professor do Collège de France... Piéron é, portanto, muito elogioso; não expressa nenhuma reserva e, segundo os testemunhos relatados por Halbwachs, ele é "excelente". Febvre e Gilson se expressam em seguida. Depois procede-se à eleição. No primeiro turno, sobre 30 votos, a proposição de Halbwachs obtém 14, a de Renaudet, 10, e a de Gouhier, 6. Como a maioria era de 16 votos, um segundo turno foi realizado e a psicologia coletiva obtém 17 votos $^{20}$. Salvo oposição do ministro (que não está formalmente encarregado de ratificar a eleição dos professores), os jogos estão feitos: nasce a cátedra de Psicologia Coletiva. Ora, precisamente, Halbwachs é um homem de esquerda que não tem seguramente o perfil do candidato ideal aos olhos do ministro da Educação nacional, Abel Bonnard. Isto explica talvez que se passe quase um ano antes que a criação da cátedra se torne oficial: o decreto só é assinado em 10 de janeiro de 1944 e publicado no Journal Officiel de 19 de janeiro.

Em 22 de fevereiro, tem lugar a votação definitiva das candidaturas (é necessário haver ao menos duas). Ninguém veio se opor a Halbwachs, para quem a cátedra está implicitamente reservada. É por puro respeito às formas administrativas que se apresenta em segunda linha Jean Stoetzel, aluno de Halbwachs, a pedido deste ${ }^{21}$. A votação ocorre sem surpresas: Halbwachs obtém os votos de 25 dos 29 presentes, Stoetzel obtém 1 voto, há três cédulas em branco e nulas. Ele é então oficialmente "apresentado em primeira linha" ao ministro da Educação nacional ${ }^{22}$. Este o nomeia professor do Collège de France por uma resolução de $1^{\circ}$ de junho de 1944.

A seqüência é bastante conhecida. Halbwachs nunca lecionará no Collège. Ele é preso pela Gestapo em 26 de julho de 1944, em decorrência das atividades de seu filho Pierre numa rede de resistência. Acreditando estar protegido por seu estatuto de professor no Collège de France, Halbwachs não procura fugir, ao contrário de sua esposa, que escapa assim à deportação. Encarcerado em Fresnes, ele é deportado para a Alemanha, ao campo de Buchenwald, onde é submetido aos trabalhos forçados e morre de doença e exaustão em 16 de março de 1945. A Assembléia de professores do Collège de France decide protestar solenemente na sessão de 12 de setembro de 1944 e encarregar o administrador Faral de escrever nesse sentido ao ministro. Esta é apenas uma parte da questão. É surpreendente de fato que os professores, ao menos alguns deles, não tenham sido mais ativos apesar da ameaça de eventuais sanções. Carcopino, por exemplo, muito mal visto pelos alemães mas que não era desprovido de influência em Vichy, 
talvez tenha sido solicitado em função de seus laços pessoais com Halbwachs. Que se passou exatamente? Não temos documentos a respeito. A história do Collège de France sob a ocupação contém muitos aspectos obscuros e está ainda por ser escrita.

\section{OS ARQUIVOS DO TEXTO}

Entre os arquivos de Maurice Halbwachs ${ }^{23}$, encontram-se quatro cadernos escolares, manuscritos, iniciados em julho de 1923 e fechados em julho de 1944. O primeiro caderno (que acaba em 1936), abre-se com as notas de leitura a propósito de La vie et l'habitude de Samuel Butler, traduzido por Valéry Larbaud em 1922. O quarto e último caderno, inaugurado em julho de 1940, termina algumas páginas após o relato retrospectivo, escrito por volta de junho de 1944, da campanha de candidatura ao Collège de France conduzida pelo narrador em 1942-1943.

Esses cadernos, redigidos às vezes paralelamente, pois as datas de três deles se sobrepõem, não pertencem a um gênero bem-definido de autobiografia. Do diário íntimo, os cadernos não podem senão tomar o nome, na medida em que Maurice Halbwachs não faz ali prova, como escreveu Gérard Namer ${ }^{24}$, de "condescendência afetiva". Também ele não busca esta perspectiva sobre si, sobre sua existência pessoal, que define, segundo Philippe Lejeune, o "pacto autobiográfico" ${ }^{25}$. A esse respeito, o auto-retrato indireto, que ele constrói em seu relato da candidatura, é certamente um dos momentos de escrita ao qual ele mais se entrega. Os cadernos não se parecem tampouco, no senso estrito, com um diário de pesquisa. Mesmo se as notas de leituras que os pontuam permitem que se siga a trama de um pensamento e de um trabalho em andamento, não se vê ali um caderno de campo ${ }^{26}$. É verdade que se percebe neles que Halbwachs começa a trabalhar nos Cadres sociaux de la mémoire a partir de 1921, o que não é indiferente, pois sabe-se que a redação dos cadernos começa em 1923. De fato, Halbwachs traça com pudor os contornos de uma subjetividade largamente aberta para a vida exterior, mas sem continuidade sistemática e segundo intervalos de tempo mais ou menos espaçados: leituras marcantes, citações, crônicas de viagem ou de férias, encontros, eventos políticos, vida universitária, familial, informações significativas ou divertidas, testemunhos sobre amigos ou personagens de sua família, palavras gentis de seus filhos.

Da marca "Studio", pautados, esses grossos cadernos de 200 páginas estão cobertos na frente e verso de uma escrita à pena, que evolui ao longo do tempo, quase sem rasuras. A paginação é do punho de Halbwachs e cada caderno termina por um índice bastante detalhado. A presença deste nos esclarece sobre o estatuto que Maurice Halbwachs concede a esses cadernos. Nem puro diário ínti- 
mo, nem verdadeiramente diário de pesquisa, os cadernos constituem para Halbwachs uma memória individual imediata na qual ele se abastece, instrumento de trabalho para abordar esta "sociedade original que cada indivíduo, de algum modo, forma consigo mesmo", segundo sua expressão. Sem dúvida, o índice está lá para ajudar a consulta de um eventual leitor, cuja curiosidade ele imagina e deseja. Assim ele escreveu no seu quarto caderno (p. 179): "Se eu cito esses testemunhos, não é por vaidade - mas para que os que lerão estas linhas, se forem meus descendentes, saibam que se dava um pouco de atenção ao que eu escrevia , no ano da graça de 1942."

A narração, linear, ocupa as páginas 191 a 248 do quarto caderno. Ela manifesta uma tal precisão que se pode perguntar se as notas diárias não teriam sido registradas numa caderneta desaparecida, se bem que no final do relato Halbwachs anuncie ter misturado a ordem das visitas.

A escrita tão particular de Halbwachs, ritmada pelas grandes barras horizontais das letras " $\mathrm{t}$ ", não trouxe nenhum problema de leitura nem de pontuação, apenas a restituição dos traços de união ausentes. Por cuidado de clareza, os títulos de obras ou de periódicos citados foram transcritos em itálico. Raros pronomes errados e nomes mal ortografados foram conservados tais como no texto.

\section{NOTAS}

${ }^{1}$ Artigo publicado inicialmente na Revue h'Histoire des sciences humaines, Villeneuve d'Ascq: Presses Universitaires du Septentrion, n. 1, p. 179-188, 1999. Tradução de Teresa Malatian.

${ }^{2}$ FOURNIER, M. Marcel Mauss. Paris, Fayard: 1994, pp. 565-590.

${ }^{3}$ Idem, p. 568, nota 1.

${ }^{4}$ MUCCHIELLI, Laurent. La découverte du social. Naissance da la sociologie en France (1870-1914). Paris: La Découverte, 1998, pp. 261-291 e 483-487.

${ }^{5}$ FOURNIER, M. op. cit., pp. 589-590.

${ }^{6}$ Não será, no entanto, reproduzida aqui a confusão feita por M. Fournier (p. 571 e ss) entre Charles e Georges Blondel. É o segundo e não o primeiro, que em 1929 se candidata ao Collège de France pela sucessão de Izoulet, de quem ele era suplente há alguns anos.

${ }^{7}$ Citado por CRAIG, J.-E. “Maurice Halbwachs à Strasbourg”. In Revue française de sociologie, 20, 1, 1979, p. 290.

${ }^{8} \mathrm{O}$ dossiê administrativo de Halbwachs (Arquivo do Collège de France, Dossier Halbwachs, C-XII) indica que, entre 1932 e 1937, ele entra para o Comité technique des sciences humaines, torna-se correspondeste da Academie des sciences morales et politiques, é eleito para o Conseil supérieur de la recherche scientifique, para o Conseil supérieur de la Statistique générale de la France e enfim para a direção (coletiva) da Statistique génerale de la France. Enfim, depois que Mauss relançou a segunda série de Année sociologique, que termina em 1927, Halbwachs se torna o principal organizador e contribuinte da nova revista dos durkheimianos, que aparece em 1934: os Annales sociologiques 
(FOURNIER, op. cit., p. 641; MARCEL, M. Les avatars de l'heritage durkheimiene. Une histoire de la sociologie en France (1920-1958). Thèse de l'Université Paris I, 1997, p. 273).

${ }^{9}$ CRAIG, J.-E. op. cit., p. 290; HEILBRON, J. Les métamorphoses du durkheimisme, 1920-1940. In Revue française de sociologie, 26, 23, 1985, p. 205. Bouglé é o principal apoio de Halbwachs na Sorbonne, os dois aproximando-se bastante durante os anos 1930.

${ }^{10}$ Ver a respeito a BLOCH, M. e FEBVRE, L. Correspondance. vol. I.. Paris: Fayard, 1994, pp. 377-384.

${ }^{11}$ Fundo Halbwachs, IMEC, Cahier 1 (juillet 1923-juillet 1936), 129-130.

${ }^{12}$ O Centre de Documentation Sociale foi criado em 1920 por Bouglé graças ao donativo de um banqueiro (MAZON,B. La Fondation Rockfeller et les sciences sociales en France, 1925-1940. Revue française de sociologia, 26, 2, pp. 313-314; 1985, MARCEL, M. Op. cit., p. 293 e ss).

${ }^{13}$ Bertrand Müller assinala essa candidatura na sua edição da correspondência entre os diretores dos Annales (BLOCH, M. e FEBVRE, L. Op. cit., p. 379, nota 168).

${ }^{14}$ WEISZ,G. "Lídéologie républicaine et les sciences sociales. Les durkheimiens et la chaire d'économie sociale de la Sorbonne". In Revue française de sociologie, 20, 1, 1979, p. 110.

${ }^{15}$ HEILBORN, J. Op. cit., p. 205.

${ }^{16}$ FOURNIER, M. Op. cit., p. 727 e ss.

${ }^{17}$ Somente na virada do século XIX para o XX, a oposição política e intelectual tradicional entre a Sorbonne e o Collège de France (os Antigos e os Modernos) desaparece, a função de professor no Collège de France adquire então o sentido de "recompensa suprema de uma carreira bem realizada".

(CHARLE, C. "Le Collège de France". In NORA, P. Les lieux de mémoire. Paris: Gallimard, v. 2 1986, p.1997, 1992).

${ }^{18}$ CRAIG, J.E. op. cit., p. 276.

${ }^{19}$ Historicamente, o Collège foi profundamente marcado pelas lutas anticlericais do século XIX. A eleição tumultuada e muito simbólica de Alfred Loisy em 1909 é sem dúvida a primeira grande manifestação desse confronto passional, ela mostra a reorganização de "um bloco anticlerical que lembra a maioria do finado ministério Combes" (CHARLE, C. Op. cit., p. 2.001).Em 1943, muitos anos haviam se passado. No entanto, pode-se aventar a hipótese de que essa clivagem marcou toda a geração dos homens nascidos no último terço do século XIX (é o caso da grande maioria dos professores do Collège nesse momento) e que, além disso, ela se encontra ao menos em parte reativada, até mesmo exacerbada pela política do governo de Vichy.

${ }^{20}$ Procès-verbal de l'Assemblée des Professeurs, 14 de março de 1943 (Archives du Collège de France, G-IV-1, pièce $11 \mathrm{w})$.

${ }^{21}$ Em seu relatório sobre os dois candidatos, Piéron apresenta Stoetzel como o "discípulo" de Halbwachs. Stoetzel tem na época 34 anos, é agrégé de filosofia, doutor em letras, encarregado de pesquisas no CNRS e chefe de um serviço de psicologia social na Fondation d'Alexis Carrel (Chaire de Psychologie collective. Relatório de M. Piéron, 27 de fevereiro de 1944, Archives du Collège de France, G-IV-1, pièce $14 \mathrm{n})$.

${ }^{22}$ Procès-verbal de l'Assemblée des Professeurs, 27 de fevereiro de 1944 (Archives du Collège de France, G-IV-1, pièce 14 o).

${ }^{23}$ Os arquivos de Maurice Halbwachs foram depositados no Institut Mémoires de l’Édition Contemporaine (IMEC) em 1947, pela senhora Lise Halbwachs-Mecarelli. Exprimimos-lhe nosso reconheci- 
mento por nos haver autorizado a publicar este texto de seu avô. Agradecemos igualmente a Christian Baudelot e a Pierre Bourdieu pelo apoio. Enfim, Jacqueline Pluet-Despatin agradece a Albert Dichy, Marina Petrenko, Pierre Despatin e Eva Telkès, pela ajuda na preparação e no comentário do texto de Halbwachs que se segue.

${ }^{24}$ NAMER, G. "Postface". In HALBWACHS, M. Les cadres sociaux de la mémoire. Paris: Albin Michel, 1994.

${ }^{25}$ LEJEUNE, P. Le pacte autobiographique. Paris: Seuil, 1975.

${ }^{26}$ LOURAU, R. Le Journal de recherche. Matériaux d'une théorie de I‘ implication. Paris: Méridiens-Klienksieck, 1988.

Artigo recebido em 06/2000. Aprovado em 11/2000. 